\title{
Hydrology-mediated invasive macrophyte impacts on freshwater mussels in a hydropeaking reservoir
}

\author{
Thomas P. Moore ${ }^{1}$, Susan J. Clearwater ${ }^{2}$, Ian C. Duggan ${ }^{1}$, and Kevin J. Collier ${ }^{1}$ \\ ${ }^{1}$ University of Waikato School of Science \\ ${ }^{2}$ New Zealand Department of Conservation
}

September 27, 2021

\begin{abstract}
Globally-threatened freshwater mussels belonging to the order Unionida (Bivalvia) may be adversely affected by dense beds of submerged macrophytes that modify habitat at the sediment-water interface. Such effects can be particularly pronounced in modified lentic ecosystems such as reservoirs which are subject to hydrological regimes (e.g., hydropeaking) that can exacerbate macrophyte-mediated impacts, including anoxic or hypoxic conditions, the related release of toxic ions (e.g., ammonia), and silt accumulation that inhibits filter-feeding. Accordingly, we compared how population size-structure and biomass of the New Zealand mussel Echyridella menziesii varied inside and outside of dense beds of invasive macrophytes known to have similar impacts on water chemistry (e.g., anoxia) in two northern New Zealand hydroreservoir locations with contrasting hydrology (lacustrine location dominated by Ceratophyllum demersum; and riverine location dominated by Egeria densa). We found adverse sediment-water interface conditions were not always associated with dense submerged macrophyte beds in littoral zones. Nonetheless, where they occurred, adverse sediment-water interface conditions were primary drivers in reduced mussel density and adult skewed size-structure, inferring reduced recruitment. Disentangling direct and indirect effects with structural equation modelling indicated that increased pore-water ammonia did not impact these primarily adult populations of freshwater mussels. Increased sediment organic matter, silt, and previously recorded hypoxia and anoxia were exacerbated in the lacustrine section where variable flows promoting water mixing were not present to reduce their effects. High densities of mussels less than $40 \mathrm{~mm}$ in length were associated with favourable sediment-water interface conditions of low silt and sediment organic matter, suggesting that enhanced water exchange in and around macrophyte beds may increase juvenile mussel survival in littoral zones of the riverine lake section. Our findings highlight a potential role for hydropeaking management in mitigating the development of adverse physicochemical conditions, and underscore the context-specific effects that dense non-native macrophyte beds can have on mussel populations.
\end{abstract}

Running head: Hydrology-mediated macrophyte effects

Hydrology-mediated invasive macrophyte impacts on freshwater mussels in a hydropeaking reservoir Thomas P. Moore ${ }^{1 *}$, Susan J. Clearwater ${ }^{2}$, Ian C. Duggan ${ }^{1}$ Kevin J. Collier ${ }^{1}$

${ }^{1}$ Environmental Research Institute, School of Science, The University of Waikato, Hamilton, New Zealand

${ }^{2}$ Department of Conservation, Hamilton, New Zealand

* Correspondence: Thomas P. Moore tom.moore.tpm@gmail.com

\section{Abstract}

Globally-threatened freshwater mussels belonging to the order Unionida (Bivalvia) may be adversely affected by dense beds of submerged macrophytes that modify habitat at the sediment-water interface. Such effects 
can be particularly pronounced in modified lentic ecosystems such as reservoirs which are subject to hydrological regimes (e.g., hydropeaking) that can exacerbate macrophyte-mediated impacts, including anoxic or hypoxic conditions, the related release of toxic ions (e.g., ammonia), and silt accumulation that inhibits filter-feeding. Accordingly, we compared how population size-structure and biomass of the New Zealand mussel Echyridella menziesii varied inside and outside of dense beds of invasive macrophytes known to have similar impacts on water chemistry (e.g., anoxia) in two northern New Zealand hydroreservoir locations with contrasting hydrology (lacustrine location dominated by Ceratophyllum demersum; and riverine location dominated by Egeria densa ). We found adverse sediment-water interface conditions were not always associated with dense submerged macrophyte beds in littoral zones. Nonetheless, where they occurred, adverse sediment-water interface conditions were primary drivers in reduced mussel density and adult skewed sizestructure, inferring reduced recruitment. Disentangling direct and indirect effects with structural equation modelling indicated that increased pore-water ammonia did not impact these primarily adult populations of freshwater mussels. Increased sediment organic matter, silt, and previously recorded hypoxia and anoxia were exacerbated in the lacustrine section where variable flows promoting water mixing were not present to reduce their effects. High densities of mussels less than $40 \mathrm{~mm}$ in length were associated with favourable sediment-water interface conditions of low silt and sediment organic matter, suggesting that enhanced water exchange in and around macrophyte beds may increase juvenile mussel survival in littoral zones of the riverine lake section. Our findings highlight a potential role for hydropeaking management in mitigating the development of adverse physicochemical conditions, and underscore the context-specific effects that dense non-native macrophyte beds can have on mussel populations.

Keywords: ecological invasions, hydropeaking, keystone species, littoral zone, New Zealand, unionids

\section{Significance statement}

Globally-threatened freshwater mussels may be impacted by macrophyte beds that modify their habitat at the sediment-water interface. In this hydroreservoir study, such impacts of increased silt, sediment organic matter, and previously recorded anoxia and hypoxia, were not always associated with macrophyte beds. However, where impacts occurred, they were exacerbated in lacustrine sites, and associated with reduced mussel density and adult-skewed population size-structures. Therefore, our findings highlight the potential role hydropeaking management can play in mitigating macrophyte-mediated adverse impacts by promoting water mixing in lacustrine environments.

\section{Introduction}

The most speciose freshwater mussel order (Unionida, Class Bivalvia) has declined in diversity markedly over the last century, as evidenced by the International Union for Conservation of Nature classifying 40 $\%$ of mussel species as Near Threatened, Threatened, or Extinct (Lopes-Lima et al. 2018). Associated with this decline has been the loss of ecosystem services and functions that dense aggregations of mussels provide, leading them to be referred to as 'umbrella', 'flagship' or 'keystone' species (Geist 2011). Mussel beds can represent biogeochemical hotspots of nutrient and resource cycling that couple pelagic and benthic ecosystem compartments, potentially increasing food-web productivity and regulating water quality through biofiltration of phytoplankton (Atkinson and Vaughn 2015).

The unique life-cycle of unionid mussels, requiring larvae (glochidia) to undergo metamorphosis on a suitable host-fish, is particularly sensitive to disruption from anthropogenic activities (e.g., that impact physicochemical stream bed characteristics; Geist and Auerswald, 2007), and may lead to recruitment failure, as indicated by adult-skewed mussel population size-structures (Modesto et al. 2017). As with all sessile benthic organisms, mussels are threatened by processes that promote adverse environmental conditions near the sediment-water interface (Andersen et al. 2017). However, interactions between recognized large-scale impacts (e.g., pollution and natural system modification; Lopes-Lima et al. 2018) and poorly documented local-scale effects of invasive species are not well known (Moore et al. 2019). Understanding such interactions 
is important for targeting mitigation measures for mussel conservation, in particular when accounting for context-specific effects on the ecosystem services mussels provide.

Invasive submerged macrophytes can be considered 'ecosystem engineers' and 'foundation species' (Ramus et al. 2017, Wood and Freeman 2017), as they frequently dominate the photic zones of lentic ecosystems where they out-compete native vegetation (Yarrow et al. 2009, Thomaz et al. 2014). These dense macrophyte beds can induce adverse environmental conditions at the sediment-water interface by altering hydrology causing hypoxia or anoxia and the associated release of toxic ions (e.g., ammonia, sulfide, and ferrous iron; Andersen et al. 2017; Ribaudo et al. 2018), and by leading to the accumulation of fine sediment (Laughton et al. 2008; Drexler et al. 2021). Benthic oxygen consumption within submerged macrophyte beds may also be increased by the decomposition of accumulated sediment organic matter which can cause prolonged anoxic and hypoxic events (Nogueira et al. 2011). In temperate regions, such impacts tend to be most extreme in late summer following peak macrophyte biomass accumulation (Madsen et al. 2001, Zohary and Ostrovsky 2011) which reduces exchange of water between the inside and outside of dense submerged macrophyte beds (Vilas et al. 2017, Torma and Wu 2019), and at the end of summer during macrophyte senescence that results in mass decomposition of organic matter (Godshalk and Wetzel 1978). Furthermore, despite the strong role plant traits can play, wind-driven mixing has been shown to buffer anoxia, even in summer and autumn (Ribaudo 2021).

Despite clear mechanistic pathways, field studies of invasive submerged macrophyte interactions with mussel density, abundance, biomass, or mortality have provided inconsistent results on the direction and magnitude of such relationships (for a review see Moore et al. 2019). For example, a study by Burlakova \& Karatayev (2007) in Texas, USA, found density of adult unionids (Pyganodon grandis andUtterbackia imbecillis ) in two lake impoundments was negatively correlated with percentage cover of Myriophyllum spicatum (50\% cover) and Nelumbo lutea (60\% cover), but not in a third lake with $10 \%$ cover of mainly non-native Chara spp. In contrast, New Zealand studies have pointed to positive relationships between density of Echyridella menziesii (Unionida: Hyriidae) and submerged macrophyte biomass in lake (Weatherhead and James 2001) and river (Nobes 1980) ecosystems, but negative relationships in other lakes (James 1985, Sorrell et al. 2007).

Human-modified environments like hydrogeneration reservoirs substantially alter hydrological regimes, with daily water level fluctuations from hydropeaking (i.e., intermittent storage and release of water through hydropower stations) related to variable inflows and outflows leading to contrasting flow conditions within the same water body. These conditions can promote establishment and determine the distribution of invasive macrophytes (Johnson et al. 2008, Havel et al. 2015), particularly in lake littoral zones (Zhao et al. 2012, Shivers et al. 2018). Reservoir management can exacerbate or mitigate the adverse environmental conditions produced by invasive submerged macrophytes near the lake-bed. For example, Moore et al. (2020) reported higher reservoir residence time led to reduced water mixing and promoted prolonged anoxic and hypoxic conditions within submerged macrophyte beds in sections of a northern New Zealand hydropeaking reservoir (also the location of the present study in both riverine and lacustrine sections). Accordingly, hydrology (i.e., riverine or lacustrine systems) may partly account for context-specific nature of mussel responses to invasive submerged macrophyte impacts at small spatial scales.

As dam construction for hydropower generation is increasing worldwide (Zarfl et al. 2014), there is a pressing need to quantify effects of the ensuing altered hydrology and environmental conditions associated with the spread of invasive submerged macrophyte species, as well as on key biota occupying highly-affected littoral zones, such as unionid mussels (Johnson et al. 2008, Khan et al. 2020). To address this need, a field study was conducted to compare mussel density and size-structure inside and outside dense invasive submerged macrophyte beds across two contrasting locations (lower-lacustrine and upper-riverine) in a northern New Zealand reservoir where the hydrology is strongly influenced by hydropeaking operations. The following hypotheses were tested: 1) dense submerged macrophyte biomass will be negatively related with the density of freshwater mussels (i.e., inside vs outside beds) ; 2) conditions (e.g., high silt) within dense macrophyte beds will be associated with a reduction in small mussel density $(<40 \mathrm{~mm})$ that is indicative of reduced recruitment; and 3) the magnitude of these effects will be moderated by reservoir hydropeaking activities 
that characterize the different hydrological regimes in the upper-riverine section (variable discharges) and lower-lacustrine section (variable water level) of the reservoir.

\section{Materials and methods}

\section{Study site}

The study was carried out in a dammed hydroelectric reservoir (Karāpiro: built in 1947) located on the Waikato River system, North Island, New Zealand ( $37^{\circ} 55^{\prime} 42.82^{\prime \prime} \mathrm{S}, 175 \mathrm{deg} 32^{\prime}$ 40.3" E). This waterbody, the most downstream in a series of eight reservoirs, has a surface area of $5.4 \mathrm{~km}^{2}$, and mean and maximum depths of $11 \mathrm{~m}$ and $30.5 \mathrm{~m}$, respectively (Lowe and Green 1987). The reservoir is considered eutrophic (Livingston 1986) with a residence time dependent on inflow: for example, minimum, mean and maximum water inflows of 208, 262 and $320 \mathrm{~m}^{3} \mathrm{~s}^{-1}$ equate to residence times of $3.3,2.6$ and 2.2 days, respectively, given the assumptions of full water column mixing and a lake water volume of $60 \times 10^{6} \mathrm{~m}^{3}$; Gibbs et al. 2015, Moore et al. 2020). Karāpiro has an upper-riverine section (hereafter riverine), where discharge from the Arapuni hydropower station produces highly variable flows (as above), and a lower-lacustrine section (hereafter lacustrine) that has a diurnally variable water level related to hydropeaking (see Moore et al. 2020).

The two most abundant macrophyte species in Karāpiro are the invasive Ceratophyllum demersum and Egeria densa (McCarter et al. 1993, Schwarz et al. 1999, Clayton et al. 2006). Ceratophyllum demersum dominates the lacustrine section where it forms extensive monospecific beds that occupy the majority of shallow littoral areas to c. $5 \mathrm{~m}$ depth (Hofstra and de Winton 2016). The riverine section is dominated by large, dense and monospecific beds of $E$. densa, which are rooted to the bottom and can withstand faster flows (Clayton et al. 2009). The rapid growth of both $C$. demersum and E. densa in spring (e.g., $2-10 \%$ day $^{-1}$ and $2-8$ $\%$ day $^{-1}$ of dry biomass, respectively; Eller et al., 2015) culminates in peak biomass at the end of autumn when beds regularly reach the water surface (Hofstra and de Winton 2016). Both species were recorded to have similar hydrology-mediated impacts on $\mathrm{pH}$, temperature, and oxygen in a previous survey (Moore et al. 2020). During the present study, three $C$. demersum sites were unexpectedly sprayed with herbicide (diquat) immediately prior to sampling causing almost complete decomposition of submerged macrophytes (1-KL, 2-MM and 3-BL in Table S1; see also Figure 1), similar to what might be expected following senescence. Accordingly, during sampling these macrophyte beds were in various stages of decomposition, which affected macrophyte biomass measurements but not paired quadrat placement (see below). Serendipitously, we had deployed a continuously monitoring sonde in one of the sprayed macrophyte beds in order to measure diurnal dissolved oxygen concentrations, which were recorded as $<1.0 \mathrm{mg} \mathrm{L}^{-1}$ for a duration of at least 10-days postspray (Moore et al. 2020).

\section{Mussel and macrophyte collection and processing}

A field survey of Echyridella menziesii density was conducted between March and April (austral summer) 2019 over 22 days at four sites in the $C$. demersum -dominated, lacustrine section and at four sites in the E. densa -dominated, riverine section (Figure 1a). Within each site, divers collected measurements from 5-6 paired quadrats $\left(1 \mathrm{~m}^{2}\right)$ placed on the bed inside (at least $2 \mathrm{~m}$ from the edge) and outside (c. 1-2 m from the edge) dense submerged macrophyte beds ( $\pm \mathrm{SD} ; 4.1 \pm 2.7 \mathrm{~m}$ distance between paired samples). Macrophyte beds comprised predominantly monospecific stands that reached the water surface and extended at least $10 \mathrm{~m}$ from the permanently inundated habitat near the shore into the lake and $50 \mathrm{~m}$ perpendicular to the shore.

Paired quadrat placements were selected to achieve similar measurement depths, and in the lacustrine section at depths not exposed during low water levels. After quadrat placement, time, GPS locations (easting, northing to $3-5 \mathrm{~m}$ ) were recorded, as well as quadrat minimum and maximum water depths. The water depth 
for each quadrat was calculated as the mean of minimum and maximum depths (during sampling), whereas slope of the bed was calculated in degrees as $\vartheta=\sin ^{-1}\left(\operatorname{Depth}_{(\max )}-\right.$ Depth (min) $)$. In total, 84 quadrats (40 lacustrine and 44 riverine) were sampled for (i) freshwater mussel density, biomass, and population sizestructure, (ii) macrophyte fresh-weight, and (iii) water and sediment physiochemical parameters (see Section 2.3). Freshwater mussels and sediments were hand-collected by gloved divers from each quadrat (excavated to c. $10 \mathrm{~cm}$ depth), placed into catch-bags, sieved (5000 $\mu \mathrm{m}$ mesh), and later measured for individual shell length, maximum width and wing-height (maximum height of the shell) using Vernier calipers (Jobmate model J701-2702; $\pm 0.5 \mathrm{~mm}$ ). Mussel live wet-weight (including the shell) was measured on an Ohaus SP4001 Scout Pro electronic scale $( \pm 0.1 \mathrm{~g})$.

Macrophytes were removed from entire quadrats outside of dense beds if present sparsely (, whereas inside beds they were sampled using a Wisconsin grab sampler (500 $\mu \mathrm{m}$ mesh; $\left.0.25 \mathrm{~m}^{2}\right)$. At two sites (2-MM and 3-BL; see Figure 1 and Table S1) macrophyte samples were unable to be collected since beds were almost completely decomposed. Macrophytes were transported on ice and frozen prior to biomass determination, and wet-weight was later determined based on methods by Bickel and Perrett (2016). Ceratophyllum demersum and $E$. densa samples were completely thawed in separate clean water baths to remove non-macrophyte material and saturate with water, spun in a manual salad spinner $(20 \mathrm{~L})$ at a constant speed for 20 turns with no-more than half of each tier filled $(<100 \mathrm{~g})$, and weighed in aluminum trays (Wedderburn W5202; \pm $0.1 \mathrm{~g}$ ). A correction was applied to account for the effect of freezing/thawing on macrophyte samples based on the wet-weight loss of six $C$. demersum and six E. densasamples pre- and post-freezing: $C$. demersum and E. densalost $\mathrm{x} \pm \mathrm{SD}=34.9 \pm 2.3 \%$ and $16.5 \pm 3.2 \%$ of initial fresh-weight, respectively, due to freezing and thawing. Final macrophyte biomass values were adjusted accordingly to provide fresh-weight.

\section{Water and sediment sample collection and analysis}

A water sample was collected with a Van Dorn sampler $(5 \mathrm{~L})$ placed horizontally $10 \mathrm{~cm}$ from the lake bottom (measurement range $5-15 \mathrm{~cm}$ from bottom) inside and outside dense macrophyte beds. From this sample, a $50 \mathrm{~mL}$ aliquot was filtered (Advantec glass fibre filter GC-50 $(0.50 \mu \mathrm{m})$ ) on shore into a $50 \mathrm{~mL}$ falcon tube for ammonia measurement in the laboratory (transported chilled in the dark). Temperature $\left({ }^{\circ} \mathrm{C}\right), \mathrm{pH}$, dissolved oxygen saturation $(\%)$, and specific conductivity $\left(\mu \mathrm{S} / \mathrm{cm}\right.$ at $\left.25^{\circ} \mathrm{C}\right)$ were recorded in the remaining water sample using calibrated meters (ProSolo, YSI Incorporated, Yellow Springs, Ohio, United States; pHTestr10, Eutech, Singapore). A sediment core was collected next to the same location using a 50 $\mathrm{mL}$ syringe tube and transferred into a $50 \mathrm{~mL}$ falcon tube for transport to the laboratory for pore-water ammonia measurement within 12 hours of field collection.

Ammonia concentrations of water and pore-water samples were determined using the phenate method (Eaton et al. 1995). Sediment sample pore-water was separated using a benchtop centrifuge (Kubota 8420; 1800 rpm for 20 minutes) and all samples were filtered again (GC-50, $0.45 \mu \mathrm{m})$ prior to analysis. Sediment organic matter content was measured using the percentage weight loss on ignition method (Heiri et al. 2001), whereby pre-weighed (Sartorius BP 221S $\pm 0.1 \mathrm{mg}$ ) aluminium foil dishes with sediment samples were dried in a 60 ${ }^{\circ} \mathrm{C}$ oven (Contherm series 5) for at least three days, weighed, and then combusted in a furnace (Nabertherm LT40/11) at $550{ }^{\circ} \mathrm{C}$ for 4 hours followed by cooling in a desiccator and reweighing to determine ash-free dry mass.

Sediment particle size analysis followed methods by Konert \& Vandenberghe (1997), whereby sample organic matter was removed using $10 \%$ hydrogen peroxide before laser grain size analysis on a Malvern Mastersizer 3000 , which quantified the percent abundance of particles between 0.01-2000 $\mu \mathrm{m}$ in diameter. Sieving separated the $<2000 \mu \mathrm{m}$ (sand and silt) from the $>2000 \mu \mathrm{m}$ (gravel) sediment fraction prior to Mastersizer measurement. Both sediment fractions were weighed (Denver Instrument Company TR-403 $\pm 0.001 \mathrm{~g}$ ) to provide percentage weight classes according to the Wentworth (1922) scale. 


\section{Data preparation and statistical analysis}

All data analyses were conducted in the R statistical software program v3.6.3 (R Core Team 2021) and presented in "ggplot2" v3.2.1 (Wickham 2016). Summary statistics of the median, mean and standard deviation were calculated for variables measured inside and outside dense macrophyte beds within each site. Detrending was performed to account for daily variability in oxygen, $\mathrm{pH}$, temperature, water depth, upstream water inflow and downstream water level related to dam operation and measurement time throughout the day (for detrending details see Moore et al. 2020).

Mussel population, site, physicochemical, and sediment characteristics (Table 1) were compared inside and outside dense macrophyte beds for the lacustrine and riverine sections using Generalized Linear Models fitted to a negative binomial distribution (i.e., for overdispersed count data; Ver Hoef \& Boveng, 2007), or factorial ANOVA with transformed data as required to meet assumptions of linearity and homogeneity of variances (i.e., logit transformation for proportion data and inverse hyperbolic sine (IHS) transformation for data with extreme values that included zero; Burbidge et al. 1988).

Relationships between mussel shell length, height, width and wet weight were investigated to select mussel variables for comparison. Model selection was used to guide if linear or polynomial models best described the relationships using the information-theoretic model-selection method (Burnham and Anderson 2002) and Akaike Information Criterion with small sample size correction $\left(\mathrm{AIC}_{\mathrm{c}}\right)$. Since length was highly related to height, width, and weight (linear, $P<0.001, \mathrm{R}^{2}=0.79$, second-order polynomial, $P<0.001, \mathrm{R}^{2}=0.85$, and fourth-order polynomial, $P<0.001, \mathrm{R}^{2}=0.98$, respectively; Figure $\mathrm{S} 1$ ), only mussel lengths were analyzed subsequently to determine differences related to population size structure. Mussel length data were binned into $5 \mathrm{~mm}$ groups and displayed as percentage histograms, with recent recruitment at each site inferred from the density of mussels less than $40 \mathrm{~mm}$ in length (equivalent to $26 \mathrm{~mm}$ height or up to 1-2 years of age based on Herath 2018).

To explore relationships between measured and detrended environmental parameters, Principal Component Analysis (PCA) was conducted in the 'Vegan' community ecology package v2.5-4 (Oksanen 2015). Prior to the PCA, imputation of missing data (e.g., primarily macrophyte fresh-weight at two sites and 23 porewater ammonia measurements; Table 1) was performed with the iterative PCA method using 'imputePCA' in the missMDA package (Dray and Josse 2015). All data were then centered and scaled (subtracted from sample means and divided by their standard deviate, respectively) to standardize measurements to the same scale (Sergeant et al. 2016). To assess statistical significance and coefficients of determination for each environmental parameter, permutation tests (999) were performed using the "envfit" function in "Vegan" (Oksanen, 2015). Freshwater mussel density was displayed on the PCA solution as contours derived from the function 'ordisurf' in which a Generalized Additive Model (GAM with negative binomial error distribution; Ver Hoef \& Boveng, 2007) fits a smoothed surface using penalized splines (Wood 2003) based on the PC1 and PC2 axes: freshwater mussel biomass contours were fitted using a GAM with Gaussian error distribution.

The form of the relationships between freshwater mussel density and environmental parameters (i.e., parameter transformations of intercept (mean), linear (none), second-order polynomial, IHS or square-root), and how these relationships changed inside and outside dense macrophyte beds and between the riverine and lacustrine sections, were explored using model selection (as above) based on AICc. Mussel density was fitted to a GLM with negative binomial distribution and a specified environmental parameter transformation (as above) with "Site" specified as a random effect. Log-likelihood ratio tests were then performed to examine if interactions should be retained in the best model; three-way interactions were retained and model assumptions of linearity and homogeneity of variances were evaluated (Supplementary material 2).

To further examine direct and indirect effects of environmental parameters on freshwater mussel density (total mussels and those $<40 \mathrm{~mm}$ in length), piecewise structural equation modelling (SEM) was performed to construct and evaluate a network of relationships in the package 'piecewiseSEM' (Lefcheck 2016). Piecewise SEM evaluates if a causal network is likely to be missing relationships by comparing the hypothesized network to a network with all possible relationships using a goodness of fit test called "directed separation". This 
produces a Fisher's C test statistic (Shipley 2000, 2009) and $P$ value, which if greater than 0.05 indicates the hypothesized network is a good fit to the data and would likely not be improved from inclusion of unspecified relationships. The AIC can be extracted from direction separation tests to compare multiple hypothesized causal networks (Shipley 2013). To test if structural equation models could be estimated based on available data, the 't rule' was followed (Grace 2006).

Prior to SEM, environmental parameters were centered and scaled to allow model convergence and produce relative effect sizes with standardized estimates (Dalal and Zickar 2012). Models were fitted by making 'site' a random effect, allowing only the intercept to vary, and comparing to a negative binomial distribution. The returned $\mathrm{R}^{2}$ values can consider variance explained only by fixed effects (marginal) or fixed and random effects (conditional) (Lefcheck, 2016). Multicollinearity between environmental parameters was examined using variance inflation factors ('vif' function in the 'car' package; Fox et al. 2018). Where multicollinearity was detected (i.e., between silt and sediment organic matter in riverine SEM), variable reduction (PCA) was conducted and the PC1 axis extracted to represent these variables. The interaction between depth and bed slope angle was specified as 'correlated error', which excludes it from the directed separation test. Standardized estimate values $(\beta)$ from SEM were not constrained to fall between +1 and -1 .

Macrophyte fresh-weight data were only available for two sites in the lacustrine section due to herbicide application (1-KL and 4-HH; $\mathrm{n}=17$; Table S1) so we excluded this variable from models containing all sites. Instead, a factor "macrophyte (inside/outside)" was included in the SEM. In addition, depth and bed slope angle were excluded due to the outlier influence of Site 4-HH found in the GLM analysis (Figure 1; Table S1). Exclusion of these variables allowed the detection of broader environmental parameter relationships with freshwater mussels across all sites; these variables were not excluded for a separate SEM for the riverine section where macrophyte spraying did not occur (see Supplementary material 3 for details).

\section{Results}

\section{Site, physicochemical and sediment characteristics}

A comparison of environmental parameters found lower average macrophyte fresh-weight (range 686-1737 $\mathrm{g}$ $\mathrm{m}^{-2} ; P<0.001$ ), depth (range 0.3-0.5 m; $P<0.001$ ) outside than inside dense macrophyte beds: no difference was found for pore water ammonia (range $0.3-1.6 \mathrm{mg} \mathrm{L}^{-1}$; non-significant at $P=0.08$ ) (Table 1). Major differences were found between lake sections, where the riverine section had higher average macrophyte freshweight (by $1383 \mathrm{~g} \mathrm{~m}^{-2} ; P<0.01$ ), bed slope angle (by $8.3^{\circ} ; P<0.05$ ) and $\mathrm{pH}$ (by $0.4 ; P<0.001$ ) and lower average depth (by $0.8 \mathrm{~m} ; P=0.001$ ) temperature (by $0.5^{\circ} \mathrm{C} ; P<0.001$ ) and pore-water ammonia (by 1.3 mg L ${ }^{-1} ; P<0.01$ ) (Table 1).

The PCA explained $27 \%$ and $15 \%$ of the variation in environmental parameters across the first and second principal components, respectively, which were associated with distinctly different environmental gradients (Figure 2; all vectors shown have $P<0.001$ ). PC1 was positively associated with silt, sediment organic matter, and pore-water ammonia, and negatively with slope and depth, whereas PC2 was positively associated with macrophyte fresh-weight, oxygen, and temperature, and negatively with water ammonia. Surprisingly macrophyte and macrophyte-free quadrats within the lacustrine section or within the riverine section had similar environmental characteristics, although they were distinctly different between sections, separating in relation to PC2 axis (Figure 2).

\section{Freshwater mussel population structure}

Neither total mussel density nor biomass were statistically different inside to outside dense macrophyte beds when examined across lake sections (Table 1). Similarly, there were no significant differences in mussel density or biomass between the lacustrine and riverine sections (Table 1). On the other hand, density of mussels $<40 \mathrm{~mm}$ in length was significantly higher on average in the riverine section compared to the lacustrine 
section (by $10.7 \mathrm{~m}^{-2}$; Table 1). Population size-structure in the lacustrine section was adult-skewed based on the low percentage of mussels found under $40 \mathrm{~mm}$ in length $(<3 \%)$ and mean length inside and outside macrophyte beds of 63-67 mm, respectively (Figure 3). In contrast, the size-structure of freshwater mussels in the riverine section supporting $E$. densabeds was bimodal both inside and outside macrophyte beds suggesting recruitment has occurred in recent years, with mussels less than $40 \mathrm{~mm}$ in length accounting between $7-26 \%$ of those collected, contributing to an overall lower mean length of $49-59 \mathrm{~mm}$, respectively (Figure 3).

\section{Relationships between mussels and environmental parameters}

Freshwater mussel density displayed a non-linear relationship across environmental parameters and the two PCA axes examined (GAM; $P<0.001, \mathrm{R}^{2}=0.22$, deviance explained $36 \%$ ) (Figure 2). Higher mussel density was associated with higher slope and depth (within the measured ranges of $0.5-4.5 \mathrm{~m}$ depth and $0-37^{\circ}$ slope), and lower mussel density was associated with higher silt, sediment organic matter, and pore-water and water ammonia. Macrophyte fresh-weight, dissolved oxygen and water temperature were associated with higher mussel density in the middle-range of their gradients (Figure 2). Mussel biomass $\left(\mathrm{g} \mathrm{m}^{-2}\right)$ displayed a similar pattern which appeared more linear amongst variables, but explained less deviance than mussel density across the two PCA axes (GAM; $P<0.001, \mathrm{R}^{2}=0.24$, deviance explained $29 \%$; Figure S2).

The relationships between freshwater mussel density and environmental parameters compared inside and outside dense macrophyte beds and between the riverine and lacustrine sections were best described by models with different environmental parameter transformations (Figure 4; see Supplementary material 2 for full details on model selection and coefficient tables). Freshwater mussel density was not statistically related to depth in the riverine section $(0-4.5 \mathrm{~m})$ since an intercept model best described the relationship: analysis of this relationship in lacustrine section did not meet model assumptions (Figure 4a). Freshwater mussel density was best explained by a model with three-way interactions $(-0.78 ; P<0.001)$ for slope angle (IHS transformation): freshwater mussel density did not significantly vary with slope angle between lake sections $(0.26 ; P=0.31)$ or inside and outside $E$. densa macrophyte beds $(0.23 ; P=0.64)$; but was significantly higher outside $C$. demersum beds in the lacustrine section with increased slope angle $(0.68$; $P<0.001$ ), driven by site $4-\mathrm{HH}$. As macrophyte fresh-weight data were influenced by or not available due to herbicide application in the lacustrine lake section, the relationship between freshwater mussel density was only examined in the riverine section, where a square-root transformation without interactions best explained the positive relationship $(0.61 ; P=0.031$; Figure 4c). In contrast, freshwater mussel density was negatively and linearly related to silt concentrations (linear; no interactions; $-0.21 ; P<0.001$ ) and silt was marginally significantly lower outside than inside macrophyte beds across both lake sections $(-0.38 ; P=0.06$; Figure 4d). Sediment organic matter best explained freshwater mussel density by a model with interactions (IHS transformation); where differences were not found between lake sections $(0.44 ; P=0.67)$ but were significantly correlated outside but not inside $C$. demersum beds in the lacustrine section $(-1.23 ; P=0.001$; Figure 4e). Pore-water ammonia best explained freshwater mussel density by a model (IHS) with three-way interaction $(1.72 ; P=0.021)$ except for inside macrophyte beds in the lacustrine section; the relationships differed significantly between lake sections and inside and outside macrophyte beds $(-2.36 ; P=0.01)$. A pronounced negative relationship between mussel density and pore water ammonia was indicated outside but not inside $C$. demersum beds in the lacustrine section in contrast to the riverine section that predicted a slightly more pronounced negative relationship inside than outsideE. densa beds (Figure 4f).

\section{Direct and indirect effects}

To determine direct and indirect effects of environmental parameters on freshwater mussel density (and density of mussels $<40 \mathrm{~mm}$ in length) between lake sections with contrasting hydrology and macrophyte species, SEM was performed across all sites (with slope, depth, and macrophyte fresh-weight excluded; see methods), as well as for the riverine section but including all variables from GLM's (Figure 5a-c). Variance explained by environmental parameters was influenced by site variability for both total mussel density $(R$ 
${ }^{2}$ marginal $\left.=0.20, R^{2}{ }_{\text {conditional }}=0.41\right)$ and density of mussels $<40 \mathrm{~mm}\left(R^{2}{ }_{\text {marginal }}=0.37, R^{2}{ }_{\text {conditional }}=\right.$ $0.62)$ across all sites, as well as in the riverine $\operatorname{SEM}\left(R^{2}{ }_{\text {marginal }}=0.23, R^{2}{ }_{\text {conditional }}=0.64\right)$.

Across all sites, freshwater mussels had a marginally significant higher density inside macrophyte beds $(\beta$ $=0.37, P<0.01$ ) that was unrelated (independence claim; $P=0.18$; S3) to the marginally significant negative direct effect of silt $(\beta=-0.27, P=0.1)$ and an indirect effect $(\beta=0.73, P<0.001)$ via sediment organic matter $(\beta=-0.41, P=0.01$; Figure $5 \mathrm{a})$. Density of mussels $<40 \mathrm{~mm}$ was significantly higher inside macrophyte beds $(\beta=0.64, P<0.001)$ and in the riverine section $(\beta=2.78, P<0.001$; Figure 5b).

In the riverine SEM, slope angle was negatively $(\beta=-0.48, P<0.01)$ and depth was positively $(\beta=0.31, P$ $=0.04$ ) related to the silt and sediment organic matter PC1 axis (explaining $93 \%$ ), which was marginally negatively related to freshwater mussel density $(\beta=-0.35, P=0.07)$. In contrast, depth had a positive indirect effect via macrophyte fresh-weight $(\beta=0.40, P=0.01)$ on mussel density $(\beta=0.47, P<0.01$; Figure 5c). In all SEM models, silt and sediment organic matter were positively related to pore-water ammonia, which in no cases was significantly related to mussel density (Figure 5; S3).

\section{Discussion}

We show that relationships of submerged macrophyte biomass with mussel density and population sizestructure in this hydropeaking reservoir differed between sites with contrasting invasive macrophyte species and hydrology (Figure 5). Across all sites, higher freshwater mussel density (and density of mussels $<40$ $\mathrm{mm}$ ) was found inside macrophyte beds, largely due to smaller mussels occurring in the riverine section where $E$. densa dominates. The relationships and patterns detected need to be interpreted in the specific context of this study, which (i) reflected daytime conditions prevailing up to $2 \mathrm{~m}$ inside submerged macrophyte beds acknowledging that conditions further inside extensive beds may be more severe, particularly at night when respiration can lead to hypoxia or anoxia at the sediment-water interface (Moore et al. 2020), and (ii) was confined to littoral zones (i.e., $<4.5 \mathrm{~m}$ water depth and not deeper parts of the reservoir outside the area of dense macrophyte colonization) subject to daily variations in depth and extent due to hydropeaking. Unexpectedly, macrophyte spraying affected three sites in the lacustrine section, creating conditions potentially similar to macrophyte collapse following senescence and providing an indication of the sustained low concentrations of dissolved oxygen (i.e., $<1 \mathrm{mg} \mathrm{L}^{-1}$ for at least 10 days) to which mussels could potentially be exposed following autumn die-off.

Somewhat unexpectedly, structural equation modelling indicated that macrophyte biomass was not related to silt, sediment organic matter, or pore-water ammonia, even though silt and sediment organic matter were implicated as the primary drivers of reduced total mussel density (but not those $<40 \mathrm{~mm}$ ) across all sites. We were unable to determine whether this difference was driven by $C$. demersumbiomass in the lacustrine section (see below) or a related mechanism (e.g., prolonged anoxic and hypoxic events). However, based on findings elsewhere, we expect that where dense invasive macrophyte beds occur in sites with low hydrological exchange, such as the lacustrine section of Karāpiro, adverse environmental conditions occur near the sediment-water interface (see Burlakova and Karatayev, 2007; Moore et al. 2020). Notwithstanding the finding that such adverse conditions were not always associated with high macrophyte biomass, where they coincided mussel density was reduced (hypothesis 1) and population size structure was adult-skewed (hypothesis 2). Furthermore, prevailing hydrology moderated these relationships such that in the lacustrine section impacts from silt and sediment organic matter were more pronounced with reduced water mixing, whereas in the riverine section rooted macrophytes able to withstand highly variable flows likely experienced water exchange within their beds to create conditions apparently suitable for juvenile mussel survival (hypothesis 3). 


\section{Hydrology-mediated effects on mussels}

Adult-skewed mussel population structure inside and outside dense $C$. demersum beds of the lacustrine section, indicative of low recruitment, could reflect prevailing physicochemical conditions creating adverse conditions for fish hosts and/or juvenile mussel survival. The non-native fish species that are abundant in Karāpiro littoral zones are known to be glochidial sinks (i.e., glochidia are able to attach but not develop in high numbers; Tremblay et al. 2016, Moore and Clearwater 2019), although a suitable native host (Gobiomorphus cotidianus) is also abundant in the lacustrine section. Thus, absence of a suitable host fish can be discounted as a reason for apparently reduced recruitment in the lacustrine section. Furthermore, evidence from a hydrogeneration lake in the South Island of New Zealand (Lake Dunstan) found G. cotidianus actively inhabit dense invasive macrophyte beds of Lagarosiphon major (Bickel and Closs, 2008), suggesting fish-hosts may not be limited by dense macrophyte beds in Karāpiro.

Rather, reduced survival of transformed juvenile mussels appears to be a more likely explanation for low recruitment in the lacustrine section. This is consistent with the cause of recruitment failure for populations of the European freshwater pearl mussel (Margaritifera margaritifera), which had limited juvenile mussel survival attributed to high levels of fine sediments, low redox potential related to low oxygen levels (at the sediment-water interface, 5 and $10 \mathrm{~cm}$ into the bed), and high bed compaction (not encountered in this study) (Geist and Auerswald 2007). Elsewhere, fine sediments accumulating within the roots of a recently introduced Ranunculus species in the River Spey (northern Scotland) have been associated with numerous dead juvenile M. margaritifera found during physical removal of macrophytes (Laughton et al. 2008).

In the present study, physicochemical measurements in the lacustrine section were influenced by the combined effects of water level variation and herbicide application at some sites. Decomposition of macrophytes postherbicide application resulted in prolonged anoxia and hypoxia of water near the bed (Moore et al. 2020), which can lead to the release of toxic ions such as ammonia, sulfide, and ferrous iron, further exacerbating adverse conditions found at the sediment-water interface (Andersen et al. 2017; Ribaudo et al. 2018). This is particularly relevant for water-pore ammonia release resulting from macrophyte decomposition (Godshalk \& Wetzel, 1978), since unionid mussels, and in particular juveniles, are among the freshwater species most sensitive to ammonia exposure (Clearwater et al. 2013; USEPA 2013). As we did not measure pore-water $\mathrm{pH}$ or temperature in-situ, we were unable to assess if our measured pore-water ammonia concentrations in the lacustrine exceeded the United States Environmental Protection Agency chronic criterion continuous concentration of $1.0 \mathrm{mg}$ Total Ammonia-Nitrogen (TAN) $\mathrm{L}^{-1}\left(\mathrm{pH} 7.8,20{ }^{\circ} \mathrm{C}\right.$ ): N.B., pore water $\mathrm{pH}$ and temperature are required to determine the proportion of TAN that is toxic unionized ammonia). Sediment pore water ammonia concentrations (i.e., TAN) were 1.7-2.3 $\mathrm{mg} \mathrm{L}^{-1}$ at the single lacustrine site that was not sprayed and notably higher at the three sprayed sites (2.3-6.7 $\mathrm{mg} \mathrm{L}^{-1}$; Table S1). Data from most unsprayed sites indicate mussels were likely present prior to spraying, and the absence of empty shells at the sprayed sites indicates on-site mortality was not widespread.

Although herbicide treatment of $C$. demersum beds in the lacustrine section limited inferences that could be made about the relationship between the macrophyte biomass and the mussel population, hydrologymediated (i.e., water level) anoxia and hypoxia events were recorded within the water column close to the bed inside dense $C$. demersum beds three months prior to the present study (see Moore et al. 2020), producing conditions likely to be lethal to juvenile mussels (Dimock and Wright 1993, Sparks and Strayer 1998). Low oxygen conditions can be inferred by high sediment organic matter content, which generates high oxygen demand for decomposition, paralleling the findings of Santos et al. (2020) and supporting the likely role of hypoxic and anoxic events in limiting mussel recruitment.

In contrast, mussel populations within dense E. densa beds in the riverine section were clearly recruiting and had higher density of mussels less than $40 \mathrm{~mm}$ at sites with greater macrophyte biomass, most likely due to the variable flow hydrology enabling greater water exchange (than in the lacustrine section) and the rooted macrophytes stabilizing mobile pumice sediments. The structural equation model suggested that $E$. densa establishes denser macrophyte beds at greater depths, within the range sampled, where shear-stress disturbance during hydropeaking is likely insufficient to dislodge mussels but sufficient to limit fine sedi- 
ment accumulation and promote sufficient water-mixing to prevent adverse physicochemical conditions from developing within macrophyte beds. This 'shear stress water-exchange' hypothesis postulates that a 'goldilocks' zone of moderate shear stress enables some macrophytes to serve as flow-refugia protecting juvenile mussels from hydropeaking effects while allowing water exchange within beds to reduce physicochemical stress (Figure 6). At shallower depths $(<1 \mathrm{~m})$ in the riverine section, macrophytes and mussels occurred at lower abundances, potentially due to hydraulic limitations from the variable-flow regime (e.g., highly variable depths, periodically high velocities). These conditions contrast to the lacustrine section where recruitment was not apparent and low water exchange in dense macrophyte beds was considered the key mechanism creating adverse physicochemical conditions.

\section{Conclusions}

We show freshwater mussel density and size-structure were related to prevailing environmental conditions, but these patterns were not primarily associated with invasive submerged macrophyte beds in littoral zones of the hydropeaking reservoir, although site-specific hydrology and macrophyte species' dominance may play a role in the distribution of mussels $<40 \mathrm{~mm}$ in length. Sediment organic matter, silt, and previously recorded hypoxia and anoxia were likely the primary factors that decreased mussel density and produced adult-skewed population size structure in the lacustrine section of the reservoir. Since evidence of reproduction (i.e., larval mussel production and suitable hosts) was found in littoral zones with suitable prevailing hydrology, improving conditions at the sediment-water interface through enhanced water exchange in and around submerged macrophyte beds may increase juvenile mussel survival. Coupling flow management with macrophyte control appears particularly important where herbicide spraying is likely to exacerbate adverse benthic conditions. These findings support the role of appropriate hydropeaking management in mitigating the development of adverse physicochemical conditions that can limit mussel population density and recruitment in and around dense invasive submerged macrophyte beds in large hydroreservoirs.

\section{Acknowledgements}

This work was funded by the Ministry of Business, Innovation and Employment (New Zealand's Biological Heritage NSC, C09X1501). The authors thank Warrick Powrie, Chris Morcom, Alice Morrison, Rex Fairweather, and student volunteers for field work assistance, Marcus Girvan for macrophyte-control reporting, Mary de Winton for client reports, and Linda Te Aho for communicating with Taumatawiiwii and Ngaati Korokii-Kahukura Trusts. The authors have no conflicts of interest to disclose.

\section{Data Availability Statement}

The data that support the findings of this study are available from the corresponding author upon reasonable request.

\section{References}

Andersen, M. R., T. Kragh, and K. Sand-Jensen. 2017. Extreme diel dissolved oxygen and carbon cycles in shallow vegetated lakes. Proceedings of the Royal Society B: Biological Sciences 284:20171427.

Atkinson, C. L., and C. C. Vaughn. 2015. Biogeochemical hotspots: temporal and spatial scaling of the impact of freshwater mussels on ecosystem function. Freshwater Biology 60:563-574.

Bickel, T.O. and Closs, G.P. 2008. Fish distribution and diet in relation to the invasive macrophyte Lagarosiphon major in the littoral zone of Lake Dunstan, New Zealand. Ecology of Freshwater Fish, 17: 10-19.

Bickel, T. O., and C. Perrett. 2016. Precise determination of aquatic plant wet mass using a salad spinner. Canadian Journal of Fisheries and Aquatic Sciences 73:1-4. 
Burbidge, J. B., L. Magee, and A. L. Robb. 1988. Alternative transformations to handle extreme values of the dependent variable. Journal of the American Statistical Association 83:123-127.

Burlakova, L. E., and A. Y. Karatayev. 2007. The effect of invasive macrophytes and water level fluctuations on unionids in Texas impoundments. Hydrobiologia 586:291-302.

Burnham, K. P., and D. R. Anderson. 2002. Model selection and multimodel inference: a practical information-theoretic approach. Springer Science \& Business Media.

Clayton, J. S., F. Matheson, and J. Smith. 2009. Lake Karāpiro weed control from March to June 2009. National Institude of Water and Atmospheric Resarach Client Report HAM2009-133, Prepared for Land Information New Zealand:14.

Clayton, J. S., R. Wells, and A. Taumoepeau. 2006. Weed control in Lake Karāpiro. National Institude of Water and Atmospheric Resarach Client Report HAM2006-130:25.

Clearwater, S. J., K. J. Thompson, and C. W. Hickey. 2013. Acute toxicity of copper, zinc, and ammonia to larvae (Glochidia) of a native freshwater mussel Echyridella menziesii in New Zealand. Archives of Environmental Contamination and Toxicology 66:213-226.

Dalal, D. K., and M. J. Zickar. 2012. Some common myths about centering predictor variables in moderated multiple regression and polynomial regression. Organizational Research Methods 15:339-362.

Dimock JR, R. V., and A. H. Wright. 1993. Sensitivity of juvenile freshwater mussels to hypoxic, thermal and acid stress. Journal of the Elisha Mitchell Scientific Society:183-192.

Dray, S., and J. Josse. 2015. Principal component analysis with missing values: a comparative survey of methods. Plant Ecology 216:657-667.

Drexler, J. Z., S. Khanna, and J. R. Lacy. 2021. Carbon storage and sediment trapping by Egeria densa Planch., a globally invasive, freshwater macrophyte. Science of the Total Environment. 755: 142602.

Eaton, A. D., L. Clesceri, and A. Greenberg. 1995. Standard methods for the examination of water and wastewater: Washington. DC, American Public Health Association.

Eller, F., A. B. Alnoee, T. Boderskov, W.-Y. Guo, A. T. Kamp, B. K. Sorrell, and H. Brix. 2015. Invasive submerged freshwater macrophytes are more plastic in their response to light intensity than to the availability of free $\mathrm{CO}_{2}$ in air-equilibrated water. Freshwater Biology 60:929-943.

Fox, J., S. Weisberg, D. Adler, D. Bates, G. Baud-Bovy, S. Ellison, and R. Heilberger. 2018. Package "car": Companion to applied regression.

Geist, J. 2011. Integrative freshwater ecology and biodiversity conservation. Ecological Indicators 11:15071516 .

Geist, J., and K. Auerswald. 2007. Physicochemical stream bed characteristics and recruitment of the freshwater pearl mussel (Margaritifera margaritifera). Freshwater Biology 52:2299-2316.

Gibbs, M., S. Safi, A. Albert, I. C. Duggan, E. Bowman, and D. Burger. 2015. Factors influencing chorophyl a concentrations in the Waikato River. National Institute of Water and Atmospheric Research Client Report HAM2014-059, prepared for Dairy New Zealand.

Godshalk, G. L., and R. G. Wetzel. 1978. Decomposition of aquatic angiosperms. I. Dissolved components. Aquatic Botany 5:281-300.

Grace, J. B. 2006. Structural equation modeling and natural systems. Cambridge University Press.

Havel, J. E., K. E. Kovalenko, S. M. Thomaz, S. Amalfitano, and L. B. Kats. 2015. Aquatic invasive species: challenges for the future. Hydrobiologia 750:147-170. 
Heiri, O., A. F. Lotter, and G. Lemcke. 2001. Loss on ignition as a method for estimating organic and carbonate content in sediments: reproducibility and comparability of results. Journal of Paleolimnology 25:101-110.

Herath, H. M. D. V. 2018. Bivalve shells as paleo-proxy archives: assessment of the usefulness as environmental and climatic recorders in the Southern Hemisphere. PhD Thesis. Macquarie University, Sydney, Australia.

Hofstra, D. E., and M. de Winton. 2016. Weed Management Plan for Hornwort in Lake Karāpiro 2016 to 2025. National Institude of Water and Atmospheric Resarach Client Report HAM2016-071.

James, M. 1985. Distribution, biomass and production of the freshwater mussel, Hyridella menziesi ( Gray), in Lake Taupo, New Zealand. Freshwater biology 15:307-314.

Johnson, P. T. J., J. D. Olden, and M. J. Vander Zanden. 2008. Dam invaders: impoundments facilitate biological invasions into freshwaters. Frontiers in Ecology and the Environment 6:357-363.

Khan, J. M., J. Dudding, M. Hart, E. Tsakiris, and C. R. Randklev. Linking life history strategies and historical baseline information shows effects of altered flow regimes and impoundments on freshwater mussel assemblages. Freshwater Biology.

Konert, M., and J. Vandenberghe. 1997. Comparison of laser grain size analysis with pipette and sieve analysis: a solution for the underestimation of the clay fraction. Sedimentology 44:523-535.

Laughton, R., P. Cosgrove, L. Hastie, and I. Sime. 2008. Effects of aquatic weed removal on freshwater pearl mussels and juvenile salmonids in the River Spey, Scotland. Aquatic Conservation: Marine and Freshwater Ecosystems 18:44-54.

Lefcheck, J. S. 2016. piecewiseSEM: Piecewise structural equation modelling in R for ecology, evolution, and systematics. Methods in Ecology and Evolution 7:573-579.

Livingston, M. E. Biggs B.J., Gifford, J.S. (1986). Inventory of New Zealand lakes. Water and Soil Miscellaneous Publication 80 \& 81200 Wellington, New Zealand, National Water and Soil Coservation Authority.

Lopes-Lima, M., L. E. Burlakova, A. Y. Karatayev, K. Mehler, M. Seddon, and R. Sousa. 2018. Conservation of freshwater bivalves at the global scale: diversity, threats and research needs. Hydrobiologia 240:1-14

Lowe, D. J., \& Green, J. D. (1987). Appendix B: Some morphometric parameters of named lakes with areas1.0 km², and some smaller lakes, in New Zealand. 471-474 in Viner, A.B. (Ed) Inland waters of New Zealand. DSIR Bulletin 241, Science Information Publishing Center, Department of Scientific and Industrial Research, Wellington.

Madsen, J. D., P. A. Chambers, W. F. James, E. W. Koch, and D. F. Westlake. 2001. The interaction between water movement, sediment dynamics and submersed macrophytes. Hydrobiologia 444:71-84.

McCarter, N. H., M. de Winton, J. S. Clayton, R. Wells, and C. Tanner. 1993. Grass carp in Lake Karāpiro: options for plant management. National Institute of Water and Atmospheric Research Client Report.

Modesto, V., M. Ilarri, A. T. Souza, M. Lopes-Lima, K. Douda, M. Clavero, and R. Sousa. 2017. Fish and mussels: Importance of fish for freshwater mussel conservation. Fish and Fisheries 19:244-259.

Moore, T. P., and S. J. Clearwater. 2019. Non-native fish as glochidial sinks: elucidating disruption pathways for Echyridella menziesiirecruitment. Hydrobiologia:1-17.

Moore, T. P., S. J. Clearwater, I. C. Duggan, and K. J. Collier. 2020. Invasive macrophytes induce contextspecific effects on oxygen, $\mathrm{pH}$, and temperature in a hydropeaking reservoir. River Research and Applications. (In Press) .

Moore, T. P., K. J. Collier, and I. C. Duggan. 2019. Interactions between Unionida and non-native species: A global meta-analysis. Aquatic Conservation: Marine and Freshwater Ecosystems:1-14. 
Nobes, R. 1980. Energetics of the freshwater mussel Hyridella menziesi (Gray). MSc thesis, University of Waikato, New Zealand.

Nogueira, F., R. Silveira, C. Da Silva, M. Abdo, P. Girard, and K. Wantzen. 2011. Hydrochemistry of lakes, rivers and groundwater. The Pantanal: ecology, biodiversity and sustainable management of a large neotropical seasonal wetland. Pensoft, Sofia-Moscow:167-198.

Oksanen, J. (2015). Multivariate analysis of ecological communities in R: vegan tutorial. University Oulu, Finland.

R Core Team 2021. R: A language and environment for statistical computing. R Foundation for Statistical Computing.

Ramus, A. P., Silliman, B. R., Thomsen, M. S., \& Long, Z. T. (2017). An invasive foundation species enhances multifunctionality in a coastal ecosystem. Proceedings of the National Academy of Sciences of the United States of America, 114(32): 8580-8585.

Ribaudo, C., J. Tison-Rosebery, D. Buquet, G. Jan, A. Jamoneau, G. Abril, P. Anschutz, and V. Bertrin. 2018. Invasive aquatic plants as ecosystem engineers in an Oligo-Mesotrophic shallow lake. Frontiers in Plant Science 9:1781.

Ribaudo, C., J. Tison-Rosebery, M. Eon., and G. Jan. 2012. Wind exposure regulates water oxygenation in densely vegetated shallow lakes. Plants. 10:1269.

Santos, R. C. L., C. T. Callil, and V. L. Landeiro. 2020. Unraveling the effects of water-sediment conditions and spatial patterns on Unionida assemblages in seasonally connected floodplain lakes. Hydrobiologia 847:2909-2922.

Schwarz, A.-M., R. Wells, and J. S. Clayton. 1999. An overview of aquatic weeds in Lake Taupo and the Waikato River. National Insitute of Freshwater and Atmospheric Research Client Report CHC98/OA:35.

Sergeant, C., E. Starkey, K. Bartz, M. Wilson, and F. Mueter. 2016. A practitioner's guide for exploring water quality patterns using principal components analysis and Procrustes. Environmental Monitoring and Assessment 188:249.

Shipley, B. 2000. A new inferential test for path models based on directed acyclic graphs. Structural Equation Modeling 7:206-218.

Shipley, B. 2009. Confirmatory path analysis in a generalized multilevel context. Ecology 90:363-368.

Shipley, B. 2013. The AIC model selection method applied to path analytic models compared using adseparation test. Ecology 94:560-564.

Shivers, S. D., S. W. Golladay, M. N. Waters, S. B. Wilde, and A. P. Covich. 2018. Rivers to reservoirs: hydrological drivers control reservoir function by affecting the abundance of submerged and floating macrophytes. Hydrobiologia 815:21-35.

Sorrell, B., N. Phillips, R. Wells, and J. Sykes. 2007. Lake Matiri assessment. National Insitute of Freshwater and Atmospheric Research Client Report: CHC2007-089.

Sparks, B. L., and D. L. Strayer. 1998. Effects of low dissolved oxygen on juvenile Elliptio complanata (Bivalvia: Unionidae). Journal of the North American Benthological Society 17:129-134.

Thomaz, S. M., R. P. Mormul, and T. S. Michelan. 2014. Propagule pressure, invasibility of freshwater ecosystems by macrophytes and their ecological impacts: a review of tropical freshwater ecosystems. Hydrobiologia 746:39-59.

Torma, P., and C. Wu. 2019. Temperature and circulation dynamics in a small and shallow lake: effects of weak stratification and littoral submerged $\mathrm{m}=$ acrophytes. Water 11. 
Tremblay, M. E., T. J. Morris, and J. D. Ackerman. 2016. Loss of reproductive output caused by an invasive species. Royal Society Open Science 3:150481.

United States Environmental Protection Agency (2013) Aquatic life ambient water quality criteria for ammonia - freshwater. EPA- 822-R-13-001. USEPA, Office of Water, Office of Science and Technology, Washington, DC.

Ver Hoef, J. M., and P. L. Boveng. 2007. Quasi-Poisson vs. negative binomial regression: how should we model overdispersed count data? Ecology 88:2766-2772.

Vilas, M. P., C. L. Marti, M. P. Adams, C. E. Oldham, and M. R. Hipsey. 2017. Invasive Macrophytes Control the Spatial and Temporal Patterns of Temperature and Dissolved Oxygen in a Shallow Lake: A Proposed Feedback Mechanism of Macrophyte Loss. Frontiers in Plant Science 8:2097.

Weatherhead, M. A., and M. R. James. 2001. Distribution of macroinvertebrates in relation to physical and biological variables in the littoral zone of nine New Zealand lakes. Hydrobiologia 462:115-129.

Wentworth, C. K. 1922. A scale of grade and class terms for clastic sediments. The Journal of Geology 30:377-392.

Wickham, H. 2016. ggplot2: elegant graphics for data analysis. Springer.

Wood, J., and M. Freeman. 2017. Ecology of the macrophytePodostemum ceratophyllum Michx. (Hornleaf riverweed), a widespread foundation species of eastern North American rivers. Aquatic Botany 139:65-74.

Wood, S. N. 2003. Thin plate regression splines. Journal of the Royal Statistical Society: Series B (Statistical Methodology) 65:95-114.

Yarrow, M., V. H. Marin, M. Finlayson, A. Tironi, L. E. Delgado, and F. Fischer. 2009. The ecology of Egeria densa Planchón (Liliopsida: Alismatales): A wetland ecosystem engineer? Revista Chilena de Historia Natural 82:299-313.

Zarfl, C., A. E. Lumsdon, J. Berlekamp, L. Tydecks, and K. Tockner. 2014. A global boom in hydropower dam construction. Aquatic Sciences 77:161-170.

Zhao, D., H. Jiang, Y. Cai, and S. An. 2012. Artificial regulation of water level and its effect on aquatic macrophyte distribution in Taihu Lake. PLoS One 7:e44836.

Zohary, T., and I. Ostrovsky. 2011. Ecological impacts of excessive water level fluctuations in stratified freshwater lakes. Inland Waters 1:47-59.

Table 1: Summary statistics (mean, median (M) and standard deviation (SD)) of environmental parameters (site, physicochemical, sediment) and mussel population characteristics. Comparisons of the upper-riverine and lacustrine sections of Karāpiro and between inside and outside macrophyte beds are shown with level of significance indicated following best-fit model tests indicated. Lake section coefficients are in relation to the upper-riverine section and macrophyte coefficients are in relation to outside macrophyte beds. Comparisons significant at $P<0.05$ are shown in bold. 


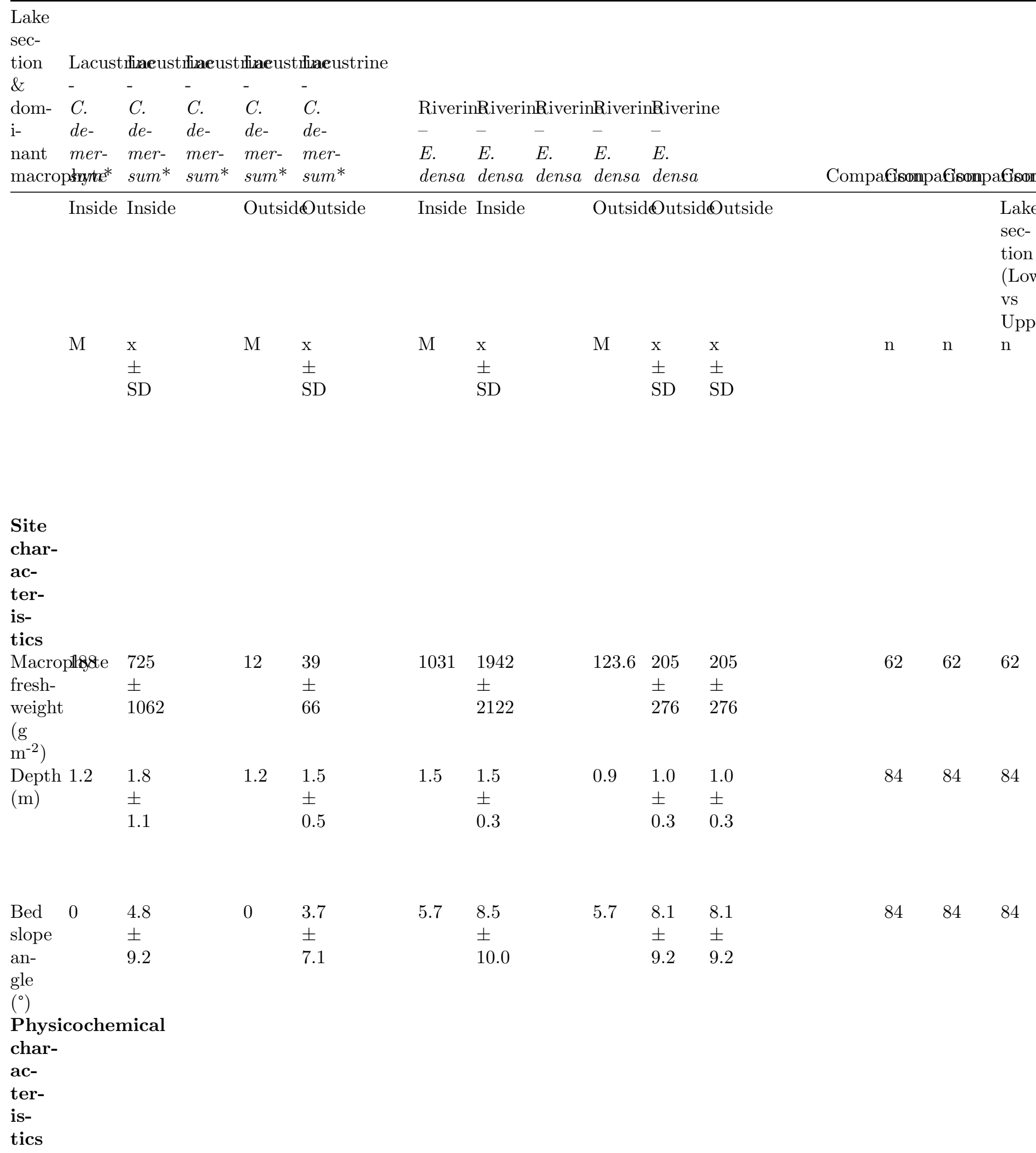

$\pm \quad \pm$




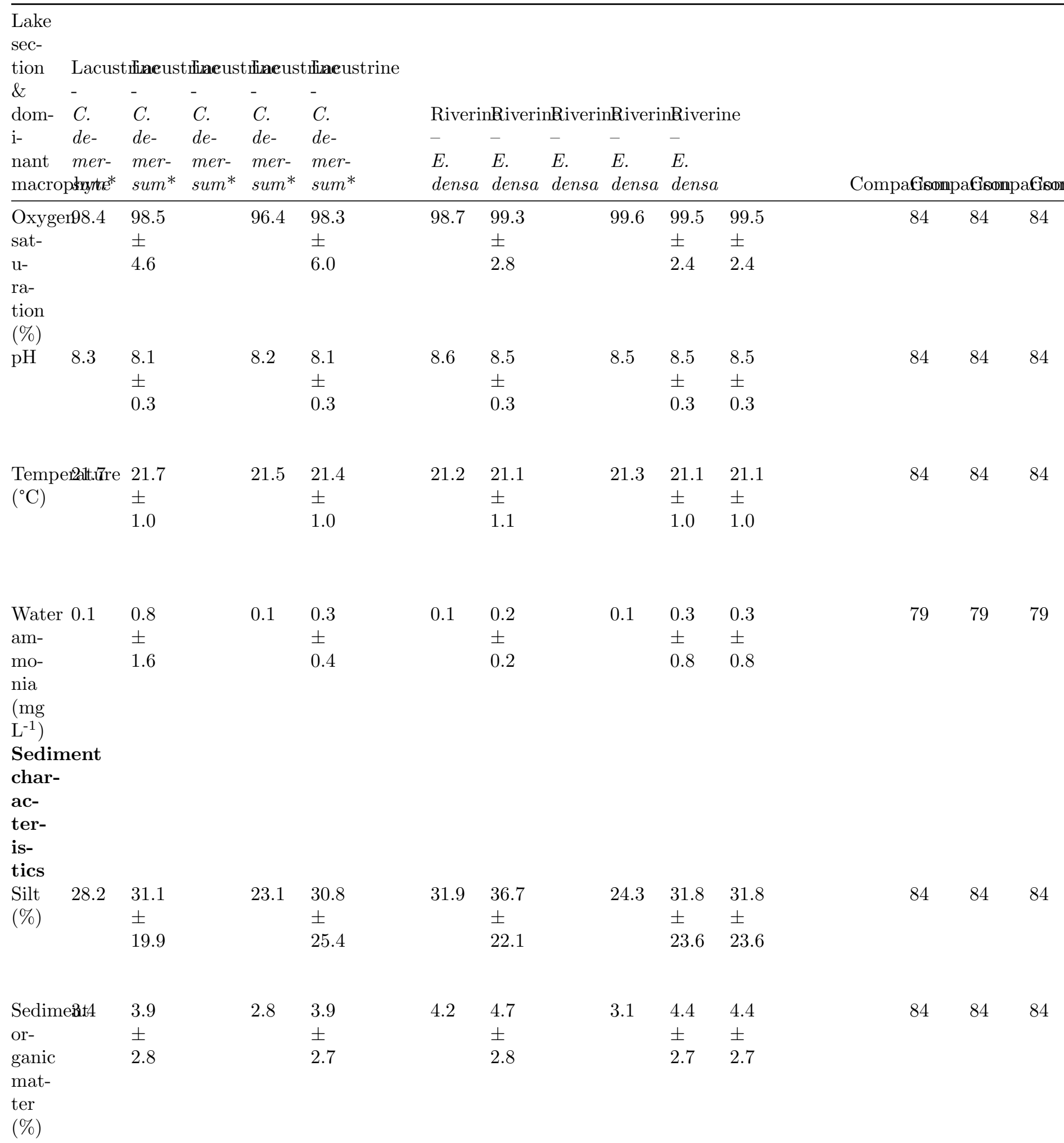




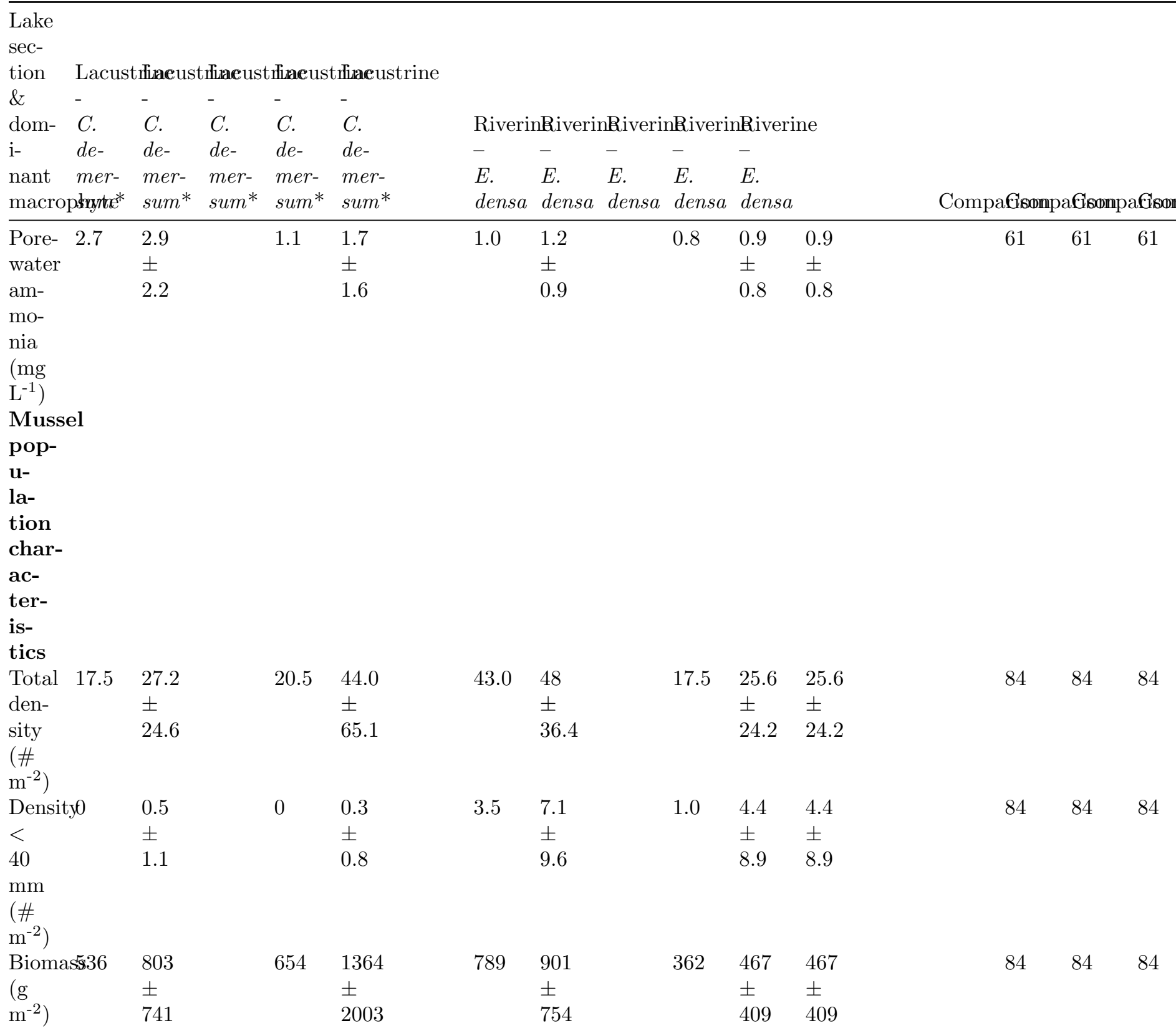

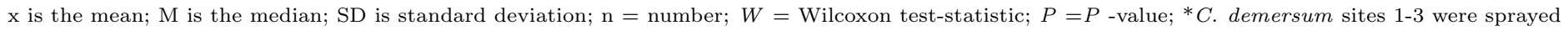

Figure 1: Study site locations (1-8) in Ceratophyllum demersum and Egeria densa beds for the lacustrine and riverine sections of Karāpiro (a), North Island, New Zealand (b). Arrows indicate flow direction.

Figure 2: Principal component plot of axes 1 and 2 in relation to measured environmental variables with vectors significant at $P<0.001$. Ellipses of sampling quadrats represent $95 \%$ standard errors for Ceratophyllum demersum lacustrine (solid outline) and Egeria densa upper-riverine (dashed outline) sections inside (dark 
green) and outside (clear) dense macrophyte beds. Contours show $10 \mathrm{~m}^{-2}$ increments for mussel density fitted with a generalized additive model (Deviance explained $=36 \%$ ). SOM $=$ sediment organic matter. Open circles indicate values for individual quadrats.

Figure 3: Mussel length distributions in $5 \mathrm{~mm}$ bins inside (dark green) and outside (white) dense macrophyte beds of (a) Ceratophyllum demersum (lacustrine) and (b) Egeria densa (upper-riverine). Mean lengths are shown for mussels collected inside (solid black line) and outside (dotted light-grey line) dense macrophyte beds.

Figure 4: Relationships of mussel density with (a) depth, (b) bed slope angle, (c) macrophyte fresh-weight, (d) silt, (e), sediment organic matter, and (f) pore-water ammonia for lower-lacustrine (circles) and upperriverine (triangles) sections inside (solid) and outside (hollow) dense macrophytes beds. Lines represent statistically significant fit of the best GLM model inside (dark green) and outside (dashed black) macrophyte beds, and dotted lines indicate non-significant GLM model fits $(P<0.1)$. Grey (outside macrophytes) or green (inside macrophytes) smooth shows $95 \%$ confidence interval.

Figure 5: Structural equation model depicting the direct and indirect effects of environmental parameters on a) mussel density and b) mussel density less than $40 \mathrm{~mm}$ across all sites, and c) mussel density in the upper-riverine lake section. Black arrows indicate positive linear relationships and red arrows negative linear relationships with standardized coefficients displayed. Solid and dashed arrows indicate statistically significant $(P<0.05)$ and non-significant relationships, respectively. $\mathrm{R}^{2}$ indicates the conditional goodnessof-fit accounting for site variability. The "Macrophyte (inside)" factor is in relation to outside the bed (i.e., presence of macrophytes was assigned a positive value) and the riverine section was assigned a positive value for "Lake section (upper-riverine)" in relation to the lacustrine section (e.g., higher mussel densities less than $40 \mathrm{~mm}$ were found inside macrophyte beds in the upper-riverine section) (see Supplementary material 3 for statistical details).

Figure 6: Conceptual diagram of the SEM results from the Karāpiro upper-riverine section inside the littoral zone. The dashed black line indicates the relationship between mussel density inside the low-disturbance deposition zone is unknown.

Figure S1: Relationships between mussel length and wing height (maximum height of the shell), width, and fresh weight with goodness-of-fit statistics and line-fit equation displayed. Solid black line is predicted linear or polynomial model fit. Dotted grey line indicate $5^{\text {th }}$ and $95^{\text {th }}$ percentiles and grey smooth shows $95 \%$ confidence interval.

Figure S2: Principle component plot of axes 1 and 2 in relation to measured environmental variables with vectors significant at $P<0.001$ and mussel biomass contours $\left(200 \mathrm{~g} \mathrm{~m}^{-2}\right)$ fitted with a generalized additive model (Deviance explained $=29 \%$ ). Ellipses envelope sampling quadrats for $C$. demersum at the lacustrine sites (solid outline) and E. densa at the upper-riverine sites (dashed outline) with (dark green fill) and without (white) fill macrophyte. $\mathrm{SOM}=$ sediment organic matter.

Table S1: Summary statistics of environmental parameters (site, physicochemical, sediment) and mussel population characteristics for each site, outside and inside dense macrophyte beds for each site. Values are means and standard deviations (SD) except for depth where the minimum (min) and maximum (max) is shown: a single number is presented if $\min$ and max are equivalent. The lacustrine section contains Ceratophyllum demersum (Sites 1-4) and riverine sectionEgeria densa (Sites 5-8) (see Table 1). Sites 1-KL, 2-MM, and 4-BL were sprayed with herbicide prior to sampling. 


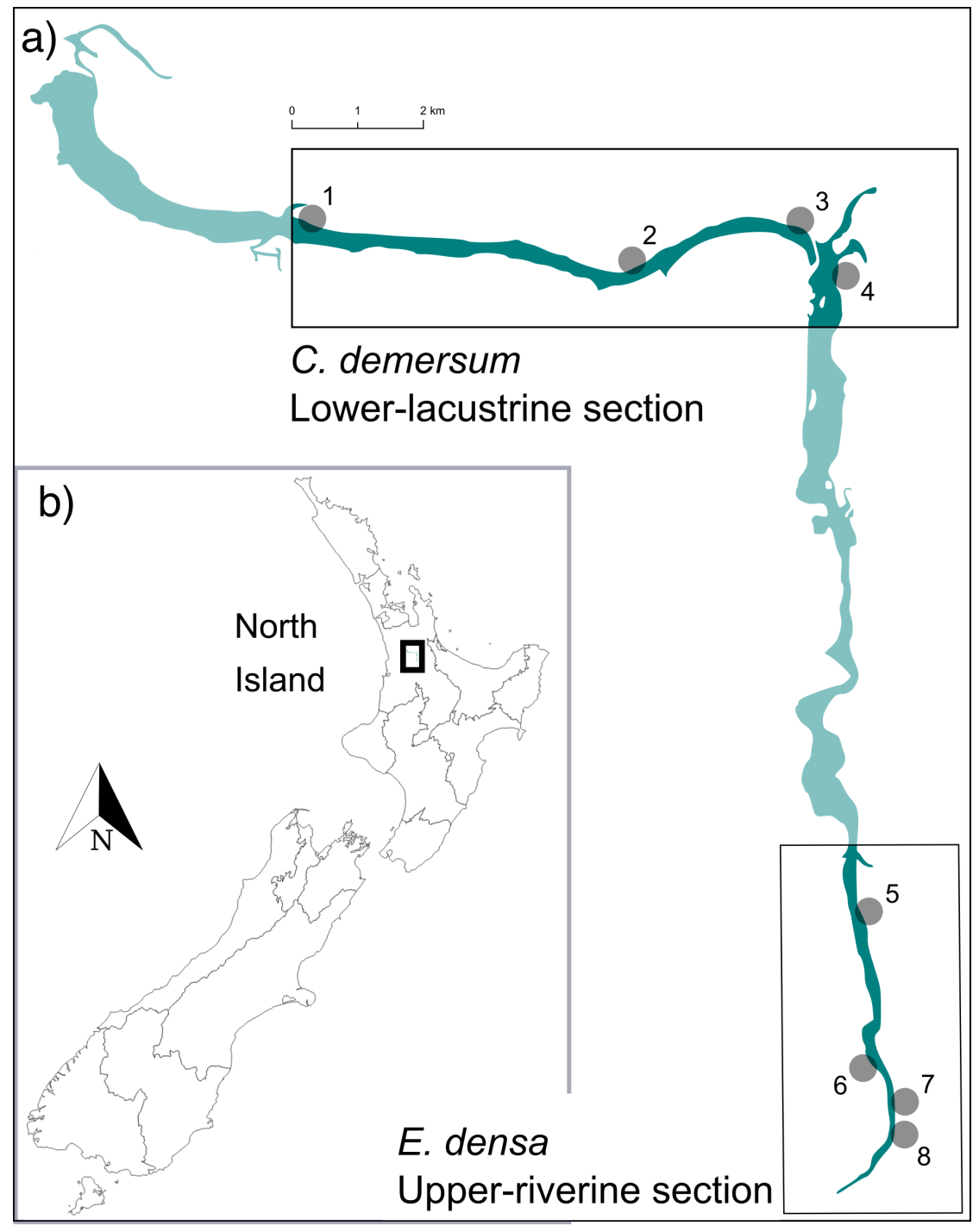




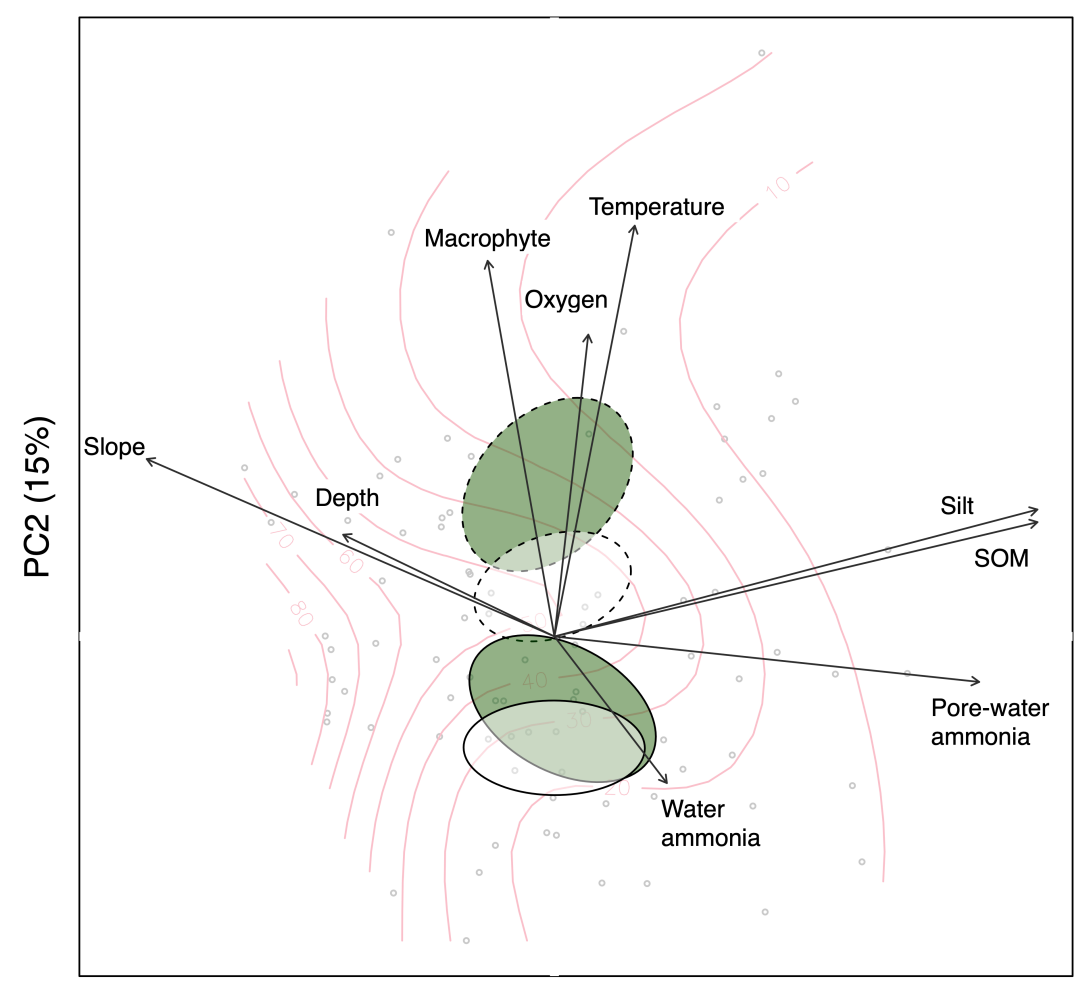

PC1 (27\%) 

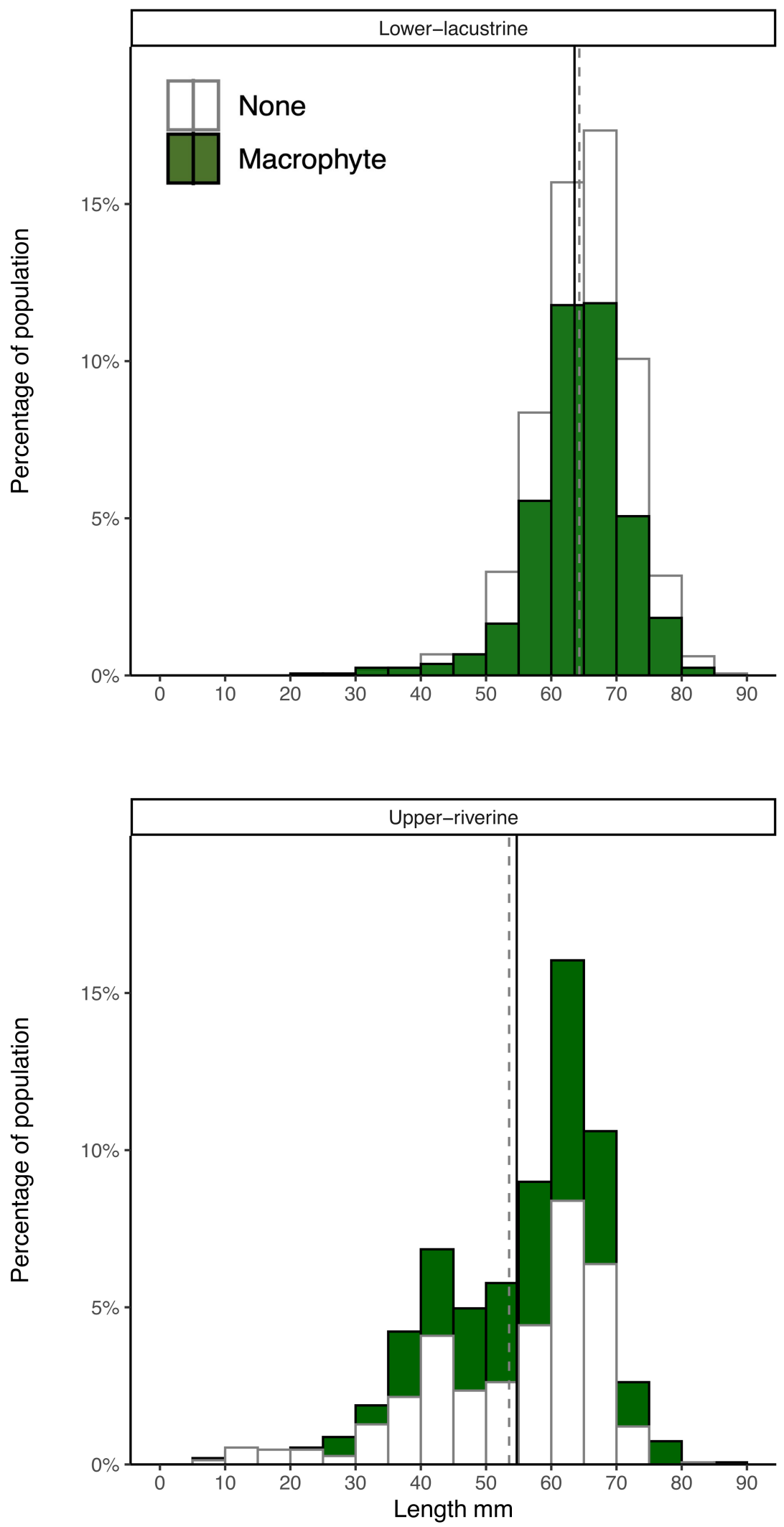

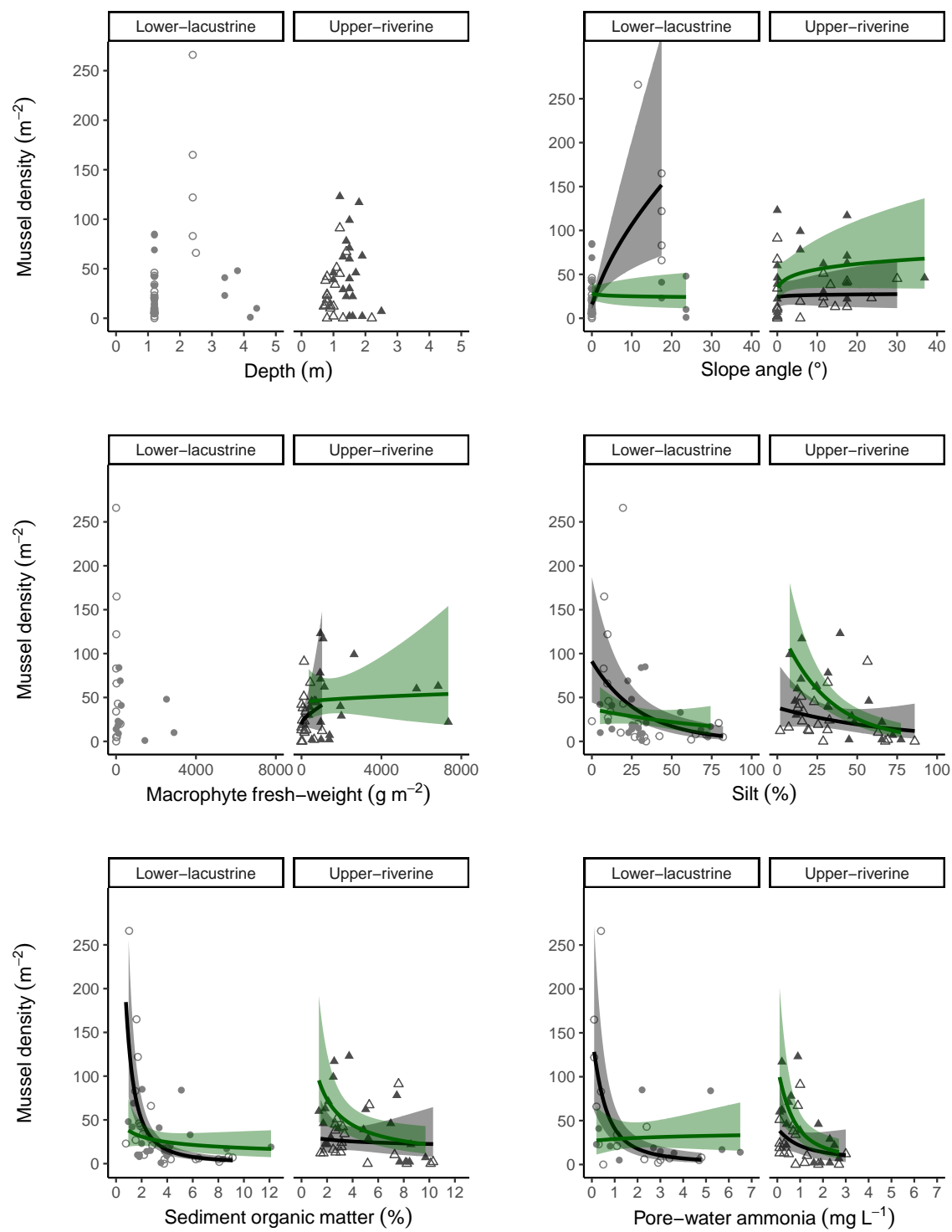

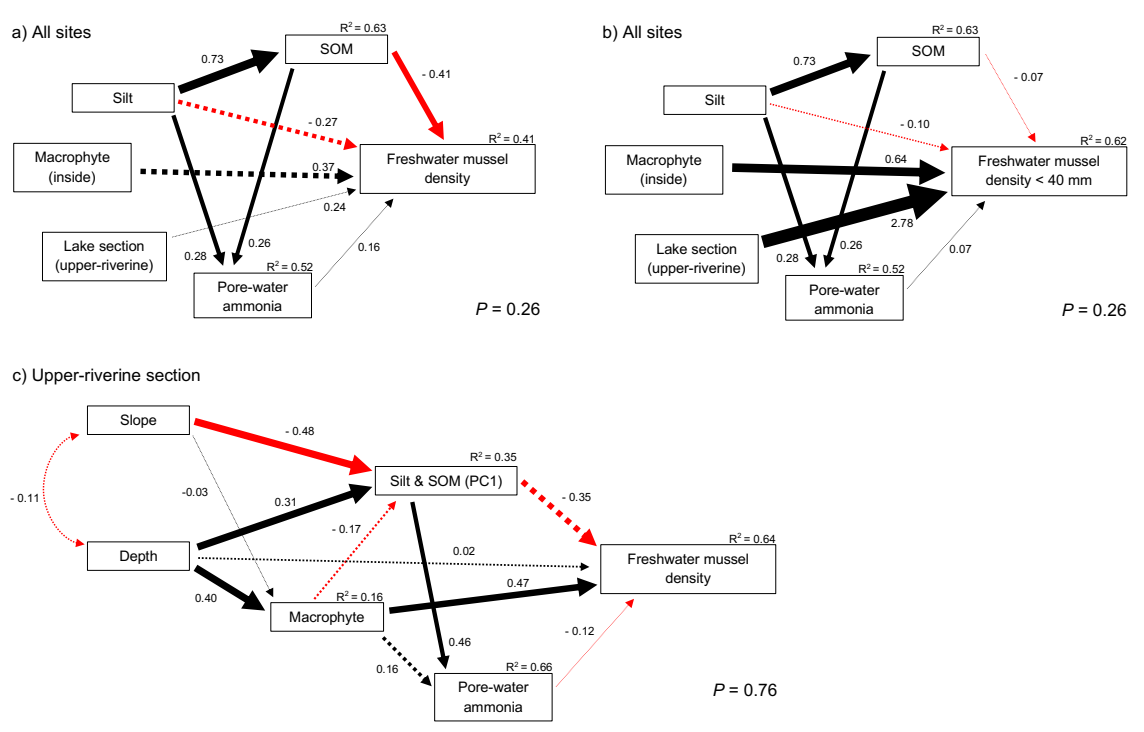


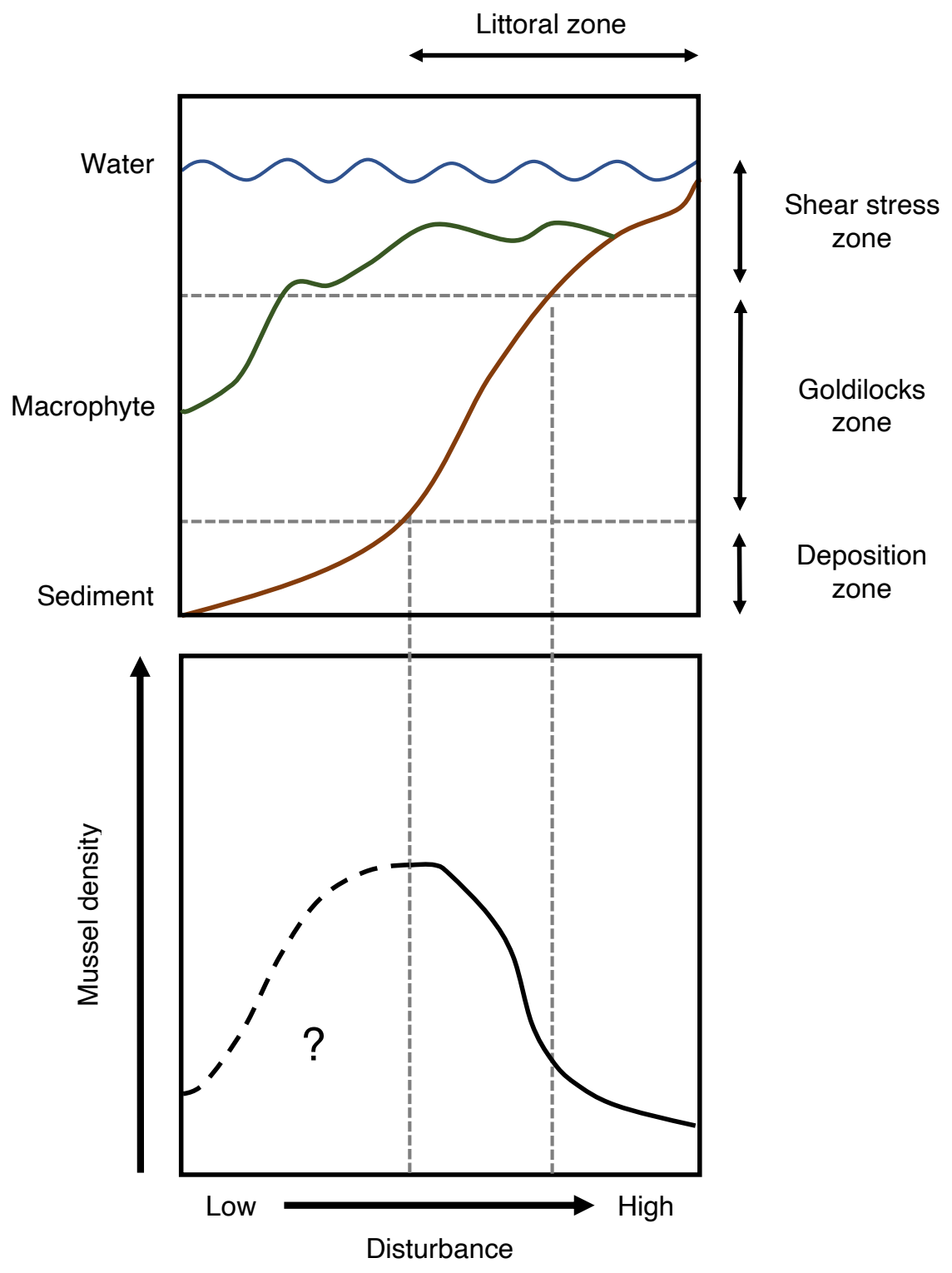

